Abstract for Crew Quarters (CQ) and Electromagnetic Interference (EMI) Measurement Facility Combined Impedance Study

This report documents an investigation into observed failures associated with conducted susceptibility testing of Crew Quarters (CQ) hardware in the Johnson Space Center (JSC) Electromagnetic Interference (EMI) Measurement Facility, and the work accomplished to identify the source of the observed behavior. Investigation led to the conclusion that the hardware power input impedance was interacting with the facility power impedance leading to instability at the observed frequencies of susceptibility. Testing performed in other facilities did not show this same behavior, pointing back to the EMI Measurement Facility power as the potential root cause. A LISN emulating the Station power bus impedance was inserted into the power circuit, and the susceptibility was eliminated from the measurements. 


\title{
Crew Quarters (CQ) and Electromagnetic Interference (EMI) Measurement Facility Combined Impedance Study
}

\author{
Robert C. Scully \\ NASA Johnson Space Center \\ Engineering Directorate \\ 2101 NASA Parkway \\ Houston, Texas 77058-3696
}

\begin{abstract}
This report documents an investigation into observed failures associated with conducted susceptibility testing of Crew Quarters (CQ) hardware in the Johnson Space Center (JSC) Electromagnetic Interference (EMI) Measurement Facility, and the work accomplished to identify the source of the observed behavior. Investigation led to the conclusion that the hardware power input impedance was interacting with the facility power impedance leading to instability at the observed frequencies of susceptibility. Testing performed in other facilities did not show this same behavior, pointing back to the EMI Measurement Facility power as the potential root cause. A LISN emulating the Station power bus impedance was inserted into the power circuit, and the susceptibility was eliminated from the measurements.
\end{abstract}

Keywords-conducted susceptibility; LISN; instability

\section{INTRODUCTION}

This report documents an investigation into observed failures associated with conducted susceptibility testing of Crew Quarters (CQ) hardware in the Johnson Space Center (JSC) Electromagnetic Interference (EMI) Measurement Facility. In brief, during conducted susceptibility testing [1] in August 2008, over the frequency range from $30 \mathrm{~Hz}$ to $50 \mathrm{kHz}$ as described in test method CS01 of International Space Station requirements documents SSP 30237 and SSP 30238, hardware susceptible behavior was observed between $880 \mathrm{~Hz}$ and $1 \mathrm{kHz}$. Subsequently, the same testing was repeated in the JSC Acoustic Test Facility [2], with no observed failures. Testing was repeated in the Acoustics Facility because the hardware was already removed from the EMI Facility, and logistics considerations precluded relocation of the hardware. Moreover, it was desirable to repeat the testing in a different facility, in order to determine if the problem was localized to the EMI Facility. The testing was repeated a second time for credit in the ATF, and the hardware certification was enabled to move forward on the recorded positive results. Discussions among a team comprising membership from the cognizant design contractor, NASA civil servant staff, and EMI Measurement Facility support contractor, determined that additional engineering evaluation testing [3] in the EMI Facility was warranted. This testing was able to replicate the originally observed failure conditions. Substitution of a Line Impedance Stabilization Network (LISN) as specified in SSP 30238, designed to emulate an output impedance very similar to that of the Station power bus impedance, eliminated the observed failure conditions. Following this testing, it was postulated that the cause of the original failure was related to the combination of the EMI Facility power supply output impedance and the CQ power input circuitry input impedance. An analysis was performed on this basis, and the results of that analysis are contained in this report.

\section{PREPARATION FOR TROUBLESHOOTING}

\section{A. Preliminary Considerations}

Pursuant to the decision to engage in troubleshooting of the initially observed anomaly, an Engineering Evaluation test procedure was discussed and written by engineering representatives from the cognizant design organization, the test support contractor, and engineering representatives from NASA JSC Avionic Systems Division. The test was designed first to replicate the successful CS01 test conducted in Building 49 , followed by a repeat of the original CS01 testing performed in Building 14. The primary difference in configuration between these two setups was the use of standalone power supplies in Building 49, and the use of the laboratory power supply in Building 14. Following the repeat of the two initial setups, troubleshooting would proceed with investigation into faulty grounding, excessive supply voltage drop, excessive applied ripple voltage, and reduced current limit setting for the laboratory power supply. In the event that all of the foregoing was unsuccessful at replicating the observed anomaly, the engineering representatives involved would then determine the next steps, if any, either to continue with additional unplanned testing, or terminate the testing and declare an unexplained anomaly. In all cases, the intent of the testing was to replicate the originally observed anomaly.

\section{B. Test Configurations and Sequencing}

The engineering evaluation test was planned to move in sequential order from one configuration to the next, based on whether the original anomaly was reproduced or not. For each configuration, a CS01 test would be performed from $0.1 \mathrm{kHz}$ to $1.5 \mathrm{kHz}$ at a standard ripple voltage level of $5 \mathrm{VRMS}$, maximum. In the event the original anomaly was captured, the test would move to a more freeform investigative phase in 
which the team would be at liberty to troubleshoot the system to focus in on the possible anomaly root cause. Table 4.1 lists the planned configurations.

The requirement for this testing was taken from SSP 30237 , and is stated as follows: "5 VRMS or $10 \%$ of the supply voltage, whichever is less, from $30 \mathrm{~Hz}$ to $2 \mathrm{kHz}$, then decreasing log-linearly to 1 VRMS or $1 \%$ of the supply voltage, whichever is less. The requirement is also met when the audio source specified in SSP 30238 adjusted to dissipate 50 watts in a $0.5 \mathrm{ohm}$ load, cannot develop the required voltage at the equipment under test (EUT) power input terminals, and the EUT is not susceptible to the output of the signal source.".

\section{TABLE I}

\section{Planned Configurations For CQ CS01 ENGINEERING EVALUATION TESTING}

\begin{tabular}{cl}
\hline \hline Configuration & \multicolumn{1}{c}{ Description } \\
\hline 1 & $\begin{array}{l}\text { Replicate Bldg 49 Setup Using Two Stand Alone Power } \\
\text { Supplies } \\
\text { Replicate Bldg 14 Setup Using One Stand Alone Power } \\
\text { Supply and the EMI Facility Power Supply } \\
\text { Power Supplies Same as \#2; Remove Electrical Bond } \\
\text { Connection Between the CQ Electrical Panel and the CQ } \\
\text { Chassis } \\
\text { Power Supplies Same as \#2; Replace Electrical Bond } \\
\text { Connection Between the CQ Electrical Panel and the CQ } \\
\text { Chassis, Insert a 6 Ohm Series Resistance to Simulate } \\
\text { Input Voltage Drop } \\
\text { Power Supplies Same as \#2; Remove Series Resistor, } \\
\text { Run CS01 With Ripple Voltage Setting Increased to 6 } \\
\text { VRMS } \\
\text { Power Supplies Same as \#2; Reduce the Current Limit } \\
\text { Setting on the EMI Facility Power Supply, Run CS01 } \\
\text { with Standard Ripple Voltage Setting of 5VRMS Level }\end{array}$ \\
\hline \hline
\end{tabular}

\section{HARDWARE INVESTIGATION}

The anomaly was observed during the testing employing configuration 5 . The test entered the troubleshooting phase at this point. The first step was to insert a $10 \mu \mathrm{F}$ capacitor at the output of the EMI Facility power supply. However, it proved not possible to operate the signal source at 6 VRMS with the capacitor in place, and in the attempt, the signal source was damaged. The capacitor was removed, and a new signal source was substituted into the circuit. The test was repeated at 800 $\mathrm{Hz}$, and the anomaly was again observed. A standalone power supply was substituted in place of the EMI Facility power supply at this point, the test repeated, and the anomaly was not observed at $700 \mathrm{~Hz}, 900 \mathrm{~Hz}$, or $1000 \mathrm{~Hz}$. The standalone power supply was removed from the circuit, and replaced with the EMI Facility power supply. A Line Impedance Stabilizer Network (LISN) was inserted in series in both the power and return leads between the CQ and the EMI Facility power supply. The test was repeated at $700 \mathrm{~Hz}, 800 \mathrm{~Hz}, 900 \mathrm{~Hz}$, and $1000 \mathrm{~Hz}$, and the anomaly was not observed. The test was repeated a second time with the signal source set to maximum output voltage capability. At this point, a full standard CS01 test was run on both the power and return leads, with no anomaly observed.

\section{Discussion of Power System StabiLity}

Power system stability has been a concern for International Space Station (ISS) power systems since the inception of the Program. A typical cause of system instability is a negative load impedance. As long as a negative load impedance is powered by a voltage source that exhibits a very low output impedance across frequency, the system will remain stable throughout its operational envelope. In cases in which the negative load impedance is powered by a source whose output impedance amplitude is larger than the negative load impedance at one or more frequencies, the system may become unstable at those frequencies. Given this situation, and the fact that ISS systems would be provided by multiple vendors and suppliers, it was determined early on to adopt the concepts first popularized by Middlebrook [4], and this adaptation was well described for large de power systems by Gholdston, et al. [5]. As discussed in [4], situations may arise wherein one is confronted by a "black box" power converter system, and the need to analyze the behavior of the combination of that "black box" and any possible filtering that might be introduced on the power input. This describes very nicely the situation with the combination of the CQ hardware power supply input and the EMI Facility power supply output combination. Given this similarity, techniques as described in [4] and [5] were used to examine the characteristics of the CQ and EMI Facility combined power bus impedance.

The techniques used were first derived in [4] for small signal considerations of combinations of source and load impedances, in particular the interaction between a dc-dc converter and its input EMI filter. From fundamental control theory, the transfer function for the system shown in Fig. 1 can be written as

$$
F_{S L}=\frac{F_{S} F_{L}}{1+\left(Z_{S} / Z_{L}\right)}
$$

where $F_{S}=$ the source transfer function

$F_{L} \quad=$ the load transfer function

$F_{S L}=$ the system transfer function

$Z_{S} \quad=$ the source output impedance

$Z_{L} \quad=$ the load input impedance

The ratio of source to load impedance can be considered as the loop gain for the integrated system. The system loop gain is used to determine the stability of the system.

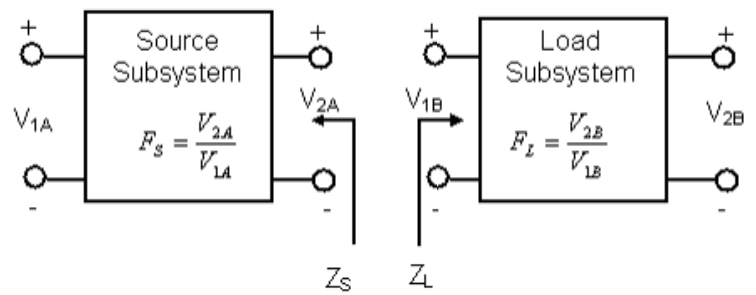

Figure 1. Impedance and Transfer Function Relationship Between A Source and Load Subsystem.

If $\left|Z_{S}\right|<\left|Z_{L}\right|$ for all frequencies, then the system is stable. If $\left|Z_{S}\right|>\left|Z_{L}\right|$, further analysis is needed to determine system 
stability. The Nyquist criterion can then be applied to the loop gain to determine system stability.

Stability requirements may be expressed in terms of gain and phase margin. To establish gain and phase margin of the transfer function, $T_{M}=Z_{S} / Z_{L}$, the first step is to establish for which frequencies, if any, $\left|Z_{S}(\mathrm{~s}) / Z_{L}(\mathrm{~s})\right|=1$. This condition is represented on a Bode plot by an intersection of the magnitude with the $0 \mathrm{~dB}$ line, or on a Nyquist plot by an intersection of the plot with the unit circle. The frequencies at which these crossings occur are known as crossover frequencies, fc. Once the $\mathrm{fc}$ are determined, phase margins at the fc are determined by identifying the phase angle of the transfer function at each fc and adding 180 degrees. Gain margin at each $\mathrm{fc}$ is then defined as the difference between the magnitude of $T_{M}$ and the $0 \mathrm{~dB}$ line on a Bode plot. On a Nyquist plot, gain margin is identified as the distance between the intersection of $T_{M}$ with the negative real axis. Fig. 2 illustrates gain and phase margins as shown on a Nyquist plot.

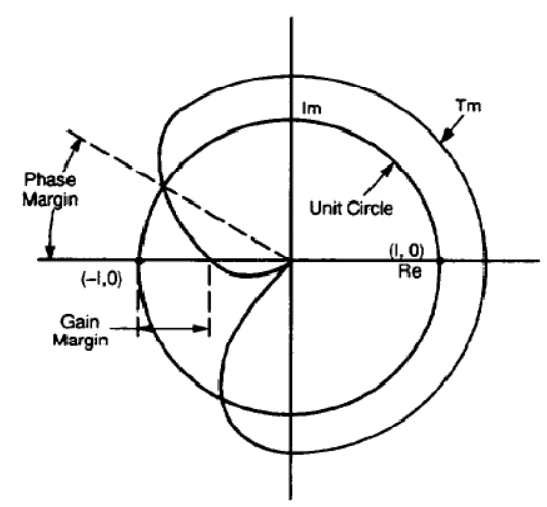

Figure 2. Nyquist Plot Gain and Phase Margins.

According to the Nyquist stability criterion, small-signal system stability is simply determined by inspection of the Nyquist plot for the system under study. If the $Z_{S} / Z_{L}$ circles the point $(-1,0)$ in the s-plane, shown as the " $\mathrm{X}$ " in the left-hand side of Fig. 3, the system is prone to be unstable. Otherwise, the system is unconditionally stable. The right-hand side of Fig. 3 shows the equivalent Bode plot representation of the Nyquist plot on the left-hand side.
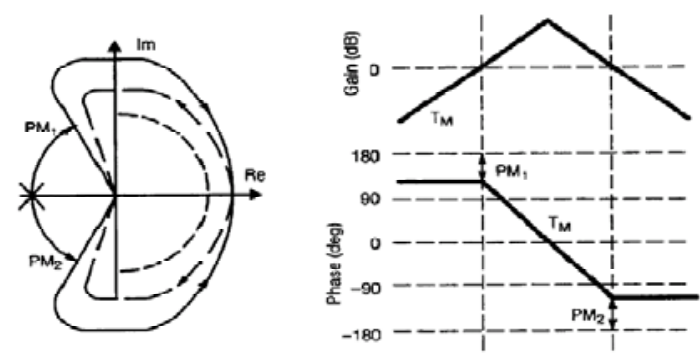

Figure 3. Impedance Criteria.

An important aspect of this theory is the realization that when the load impedance magnitude exceeds that of the source impedance, a negative load impedance condition exists. This is illustrated in Fig. 4, wherein the load and source impedances can be seen to overlap at two different frequencies. These are crossover frequencies, as discussed previously, and a corresponding gain and phase margin exist at each point.

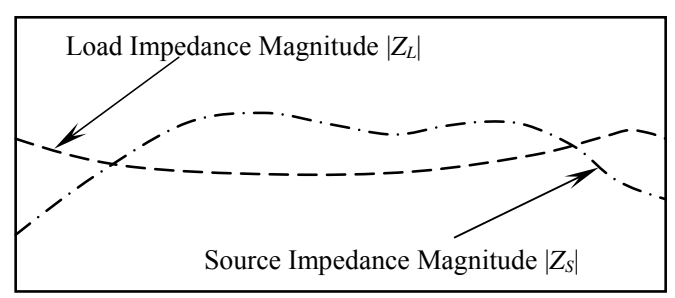

Figure 4. Source and Load Impedance Crossover.

Bus impedance peaking may occur at such points of overlap. The bus impedance, $Z_{B U S}$, is defined as the parallel combination of $Z_{S}$ and $Z_{L}$.

$$
Z_{\text {BUS }}=Z_{S} \| Z_{L}=\frac{Z_{S}}{1+\left(Z_{S} / Z_{L}\right)}=Z_{S}\left(\frac{1}{1+\left(Z_{S} / Z_{L}\right)}\right)
$$

Peaking, a manifestation of bus resonance, occurs at the fc, and is a function of the phase margin. When the phase margin is small, the factor on the right hand of equation (2) is less than 1 , and peaking will occur. Conversely, if the phase margin is large, the factor is greater than 1 , and no peaking occurs. This effect is illustrated in Figs. 5 and 6.

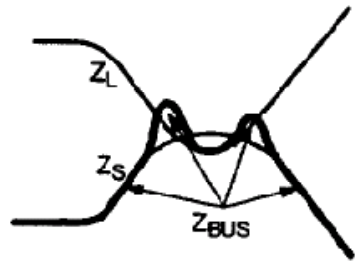

Figure 5. Small Phase Margin Bus Z Peaking.

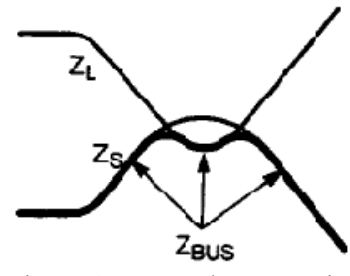

Figure 6. Large Phase Margin Bus Z Peaking.

\section{ANALYSIS RESULTS}

Data collected from all CS01 testing strongly suggested the EMI Facility power supply was entering into a current limit state. In particular, measurements and observations made during the engineering evaluation testing illustrated this effect, even though the current limit of the supply was set above the expected current maximum, the maximum being controlled by means of an inline fuse. This behavior in turn suggested the combination of the Crew Quarters and the EMI Facility power supply bus impedances was such that bus peaking was occurring between $880 \mathrm{~Hz}$ and $1 \mathrm{kHz}$, such as described in the preceding theory. In order to pursue this train of thought, references [6], Summary of the EMI Lab Power Supply Output Impedance Test, and [7], Quick Look Data Package Revised Crew Quarters (CQ) Electrical Power Quality Test, were obtained, as well as the impedance - frequency relationship of the Space Station LISN [8], and the individual and combined bus impedances were determined as a function of frequency. The resulting plots of these curves are shown in Figs. 7 and 8. 
What the first curve illustrates is the comparison of the Crew Quarters input impedance and the EMI Facility power supply output impedance, and the combined bus impedance of the two. It can be seen that between approximately $1 \mathrm{kHz}$ and $2 \mathrm{kHz}$, the EMI Facility power supply output impedance is well above the Crew Quarters input impedance, a region of negative load impedance for this combination. Indeed, as theory would predict, just below $1 \mathrm{kHz}$, the combined bus impedance shows a marked peaking, or resonant, response. This resonance is almost certainly the cause for the EMI Facility power supply current limit response during the Crew Quarters CS01 testing. The second curve illustrates the Crew Quarters input impedance and the output impedance of the Space Station LISN that was inserted in-line with the EMI Facility power supply output during the engineering evaluation testing. It is clear from this curve that for all frequencies the LISN impedance is well below the Crew Quarters input impedance, and the resulting combined bus impedance does not exhibit any peaking behavior.

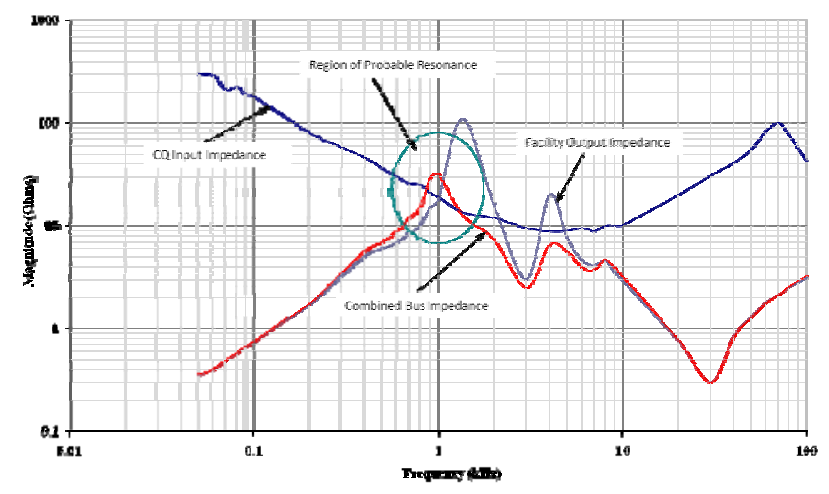

Figure 7. Crew Quarters Input Impedance, EMI Facility Output Impedance, and Combined Bus Impedance, without LISN

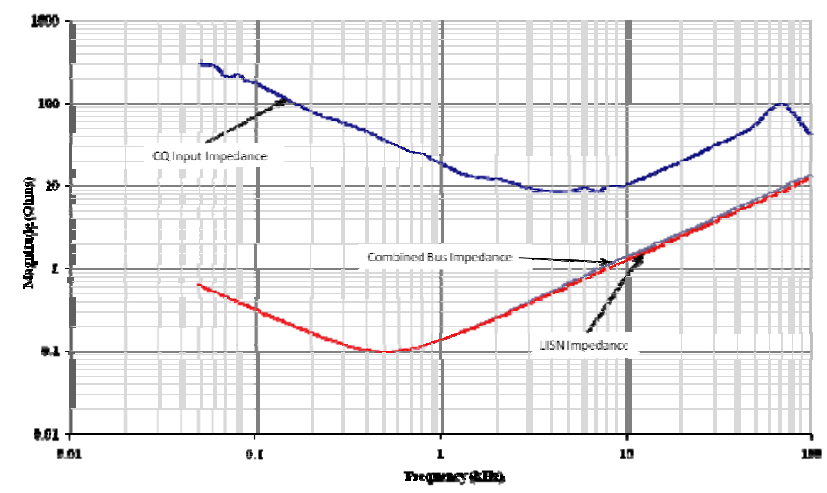

Figure 8. Crew Quarters Input Impedance, EMI Facility Output Impedance, and Combined Bus Impedance, with LISN

\section{CONCLUSION}

Based on the foregoing analysis, coupled with the information contained in the preceding theoretical discussion, it is concluded the observed anomalous behavior of the Crew Quarters hardware in the EMI Facility was in fact the result of the interaction of the Crew Quarters input impedance and the EMI Facility output impedance. Substitution of the Space Station LISN, designed to emulate the impedance of the Space Station bus in orbit, eliminated the anomalous behavior entirely, and together with the results from the Building 49 testing, further demonstrated the Crew Quarters hardware is in compliance with its CS01 EMI requirement.

\section{REFERENCES}

[1] D. M. Tran, "EV5-07-EMC-020R - EMI Test Report for the Certification of the International Space Station (ISS) Crew Quarters (CQ)", Johnson Space Center, Houston, Texas, 10 October 2008.

[2] H. Ngo, "EV5-08-EMC-021R - Amendment to EV5-07-EMC-020R EMI Test Report for the Certification of the International Space Station (ISS) Crew Quarters (CQ)", Johnson Space Center, Houston, Texas, 29 October 2008.

[3] Task Performance Sheet (TPS) EF082XXX, "Engineering Evaluation of the CQ Rack for CS01 EMI Testing", Johnson Space Center, Houston, Texas, 3 November 2008.

[4] R.D. Middlebrook, "Input Filter Considerations in Design and Application of Switching Regulators", in Proc. IEEE Industry Applications Society Annual Meeting, Chicago, 1976.

[5] E.W. Gholdston, K. Karimi, F.C. Lee, J. Rajagopalan, Y. Panov, B. Manners, "NASA Technical Memorandum 107281-Stability of Large DC Power Systems Using Switching Converters, With Application to the International Space Station", presented at the 31st Intersociety Energy Conversion Engineering Conference, Washington, DC, Aug. 1116, 1996, Paper IECEC 96-96079.

[6] J. C. Neeley, Lockheed Martin Memorandum, "Summary of the EMI Lab Power Supply Output Impedance Test", Johnson Space Center, Houston, Texas, 7 September 1999.

[7] Energy Systems Test Branch Report ESTA-DP-7X019Q, "Quick Look Data Package Revised Crew Quarters (CQ) Electrical power Quality Test", Johnson Space Center, Houston, Texas, 21 October 2008.

[8] Figure 3.2.1.3.2-1 LISN for CE07 Measurements, "SSP 30238, Space Station Electromagnetic Techniques, Revision E”, Johnson Space Center, Houston, Texas, 31 July 2002. 